\title{
The association between weight, height, and head circumference reconsidered
}

\author{
Christiane Scheffler ${ }^{1}$, Holle Greil' and Michael Hermanussen ${ }^{2}$
}

BACKGROUND: Under normal nutritional and health conditions, body height, weight and head circumference are significantly related. We hypothesize that the apparent general association between weight, height, and head circumference of the growing child might be misleading.

METHODS: We reanalyzed data of 7,444 boys and 7,375 girls measured in East-Germany between 1986 and 1990, aged from 0 to $7 \mathrm{y}$ with measurements of body length/height, leg length, sitting height, biacromial shoulder breadth, thoracic breadth, thoracic depth, thoracic circumference, body weight, head volume, percentage of body fat, and hip skinfold vertical, using principal component analysis.

RESULTS: Strong associations exist between skeletal growth, fat accumulation, and head volume increments. Yet in spite of this general proportionality, skeletal growth, fat acquisition, and head growth exhibit different patterns. Three components explain between almost $60 \%$ and more than $75 \%$ of cumulative variance between birth and age $7 \mathrm{y}$. Parameters of skeletal growth predominantly load on the first component and clearly separate from indicators of fat deposition. After age of $2 \mathrm{y}$, head volume loads on a separate third component in both sexes indicating independence of head growth.

CONCLUSION: Under appropriate nutritional and health circumstances, nutritional status, body size, and head circumference are not related.

$\mathbf{T}$ he association between nutrition and brain development has extensively been studied not only in malnourished (1), but also in wealthy European populations. Correia and coworkers (2) found birth weight and birth head size to be associated with head size and cognitive abilities in childhood and adult life, and postulated that cognitive abilities could have acted as selective pressure responsible for the newborn fatness increase. Räikkönen et al. (3) showed that small head circumference at birth predicted poorer verbal, visuospatial, and arithmetic abilities, and that slow weight gain between birth and age 6 mo, between ages 6 mo and $2 \mathrm{y}$, or both predicted poorer performance.
Kuzawa and coworkers (4) discussed metabolic costs and evolutionary implications of human brain development. They found that human brain glucose demands peak during childhood around an age of $5 \mathrm{y}$. The authors provided evidence that brain metabolism and body growth rate covary inversely across development, and hypothesized that the high costs of human brain development require compensatory slowing of body growth rate. These and similar findings have recently led to vivid discussions about the impact of brain growth, head circumference, and cognitive development on height and weight increments during early childhood. Leading nutritionists even argued that during periods of peak head growth, height, and weight increments may substantially be impaired (personal communications 2015). These rather general associations between weight, height, and head circumference of the growing child are still used to justify world-wide nutrition programs already at early age.

Yet, this view might be deceptive. There is no doubt that under normal nutritional and health conditions, body height, weight, and head circumference are significantly related. This is true for all ages and reflects the general proportionality in the human form (5). However, it is less clear whether this general proportionality persists when applying more sophisticated statistical tools for the analysis of interactions between the accumulation of fat, growth of the skeletal system and the increase in head size. We hypothesize that the apparent general association between weight, height, and head circumference of the growing child is misleading and gives rise to misinterpretation. We tested this hypothesis in body length/height, leg length, various body diameters and circumferences, body weight, percentage of body fat, and idealized head volume in 7,444 boys and 7,375 girls, aged 0-7 y, from East Germany measured between 1986 and 1990 .

\section{METHODS}

We reanalyzed a large data set of 7,444 boys and 7,375 girls aged from 0 to $7 y$ at 12 age groups $(0-0.25-0.5-0.75-1.0-1.5-2-3-4-5-6-7$ $\mathrm{y}$; age calculation is centered) measured in East-Germany between 1986 and 1990, with measurements of body length or after age 2 y body height $(\mathrm{BH})$, sitting height $(\mathrm{SH})$, leg length (LL, calculated as difference of $\mathrm{BH}-\mathrm{SH}$ ), biacromial shoulder breadth, thoracic breadth,

'Department of Human Biology, Institute for Biochemistry and Biology, Universität Potsdam, Potsdam, Germany; ${ }^{2}$ Aschauhof, Eckernförde-Altenhof, Germany. Correspondence: Michael Hermanussen (michael.hermanussen@gmail.com)

Received 12 September 2016; accepted 3 November 2016; advance online publication 1 March 2017. doi:10.1038/pr.2017.3 
Table 1. Three principal components are sufficient to explain between almost $60 \%$ and more than $75 \%$ of the cumulative variance (see Figures 2 and 3)

\begin{tabular}{|c|c|c|c|c|c|c|}
\hline Age group (y) & Decimal age & $n$ & $\begin{array}{c}\% \text { variance } \\
\text { comp. } 1\end{array}$ & $\begin{array}{c}\text { \% variance } \\
\text { comp. } 2\end{array}$ & $\begin{array}{c}\% \text { variance } \\
\text { comp. } 3\end{array}$ & $\begin{array}{l}\% \text { variance } \\
\text { cumulative }\end{array}$ \\
\hline \multicolumn{7}{|l|}{ Male } \\
\hline 0.25 & $0.15-0.349$ & 403 & 36.36 & 14.13 & 12.15 & 62.63 \\
\hline 0.5 & $0.35-0.625$ & 410 & 34.8 & 17.88 & 9.74 & 62.42 \\
\hline 1.5 & $1.125-1.75$ & 244 & 33.88 & 18.98 & 9.93 & 62.79 \\
\hline 2 & $1.75-2.25$ & 434 & 35.93 & 17.06 & 9.7 & 62.68 \\
\hline 3 & $2.5-3.49$ & 1,020 & 40.3 & 16.93 & 9.67 & 66.9 \\
\hline 4 & $3.5-4.49$ & 782 & 44.69 & 16.09 & 9.04 & 69.82 \\
\hline \multicolumn{7}{|l|}{ Female } \\
\hline Newborn & $0-0.05$ & 174 & 39.3 & 14.06 & 11.5 & 64.85 \\
\hline 0.25 & $0.15-0.349$ & 375 & 44.97 & 14.01 & 11.13 & 70.11 \\
\hline 0.5 & $0.35-0.625$ & 424 & 33.37 & 15.84 & 12.15 & 61.35 \\
\hline 0.75 & $0.626-0.875$ & 482 & 35.79 & 17.13 & 9.94 & 62.86 \\
\hline 1 & $0.876-1.125$ & 335 & 31.38 & 16.24 & 11.22 & 58.84 \\
\hline 1.5 & $1.125-1.75$ & 242 & 37 & 15.72 & 10.65 & 63.37 \\
\hline 2 & $1.75-2.25$ & 435 & 38.49 & 13.81 & 9.81 & 62.11 \\
\hline 3 & $2.5-3.49$ & 1,017 & 42.29 & 16.84 & 9.4 & 68.53 \\
\hline
\end{tabular}

thoracic depth, thoracic circumference, body weight (mass), and idealized head volume (HV, calculated as ellipsoid determined by head length (HL), head breadth (HB) and the difference between $\mathrm{BH}$ and tragion height, $\mathrm{TH}$ ). Idealized head volume was chosen as this parameter was considered to better represent brain growth than head circumference, or either one of the three one-dimensional parameters head length, head breadth, and tragion height that all load on the same component (data not shown). In addition, we determined percentage of body fat (BF, calculated from two skinfolds (SF: triceps, subscapular)). As total body fat differentiates between sexes and corrects for obesity, it better represents the nutritional component of a particular individual than just the two skinfolds. In addition, we determined hip skinfold vertical. All measures were collected under standardized conditions (6).

The BMI, the percentage of body fat $(\% \mathrm{BF})$ and the $\mathrm{HV}$ were calculated with the following formulas:

(1) $\mathrm{BMI}=$ weight $(\mathrm{kg}) /$ height $^{2}\left(\mathrm{~m}^{2}\right)$

(2) $\dagger \Sigma \mathrm{SF}=\mathrm{SF}$ triceps $+\mathrm{SF}$ subscapular

$(3) \dagger \% \mathrm{BF}\left(\right.$ girls $\left._{\Sigma \mathrm{SF}>35 \mathrm{~mm}}\right)=0.546(\Sigma \mathrm{SF})+9.7$

$(4) \dagger \% \mathrm{BF}\left(\right.$ girls $\left.{ }_{\Sigma \mathrm{SF}}>35 \mathrm{~mm}\right)=1.33(\Sigma \mathrm{SF})-0.013(\Sigma \mathrm{SF})^{2}-2.5$

(5) $\dagger \% \mathrm{BF}\left(\right.$ boys $\left.{ }_{\Sigma \mathrm{SF}>35 \mathrm{~mm}}\right)=0.783(\Sigma \mathrm{SF})+1.6$

(6) $\dagger \% \mathrm{BF}$ (boys $\left.\sum_{\Sigma \mathrm{SF}}>35 \mathrm{~mm}\right)=1.21(\Sigma \mathrm{SF})-0.008(\Sigma \mathrm{SF})^{2}-1.7$

(7) $\ddagger \mathrm{HV}=4 / 3 \cdot \pi \cdot \mathrm{sF} \cdot \mathrm{HL} \cdot \mathrm{HB} \cdot(\mathrm{BH}-\mathrm{TH})$

$(\dagger$ after $(7))$

( $\ddagger$ different methods exist to estimate cranial volume (8), yet as all these estimates are based on external measures of head length, head breadth, and head height without reference to individual skull thickness, we preferred applying the simple formula for ellipsoids.)

We applied principal component analysis (PCA) (Table 1), and checked the nonparametric correlation of the variables. Because of the correlation between the variables we used the Oblimax rotation method with Kaiser normalization (9). The Kaiser-Meyer-Olkincriteria were checked $(\mathrm{KMO}>0.75)$. In each age group we were able to extract three main components that explained depending on age between almost $60 \%$ and more than $75 \%$ of the cumulative variance (Table 1). PCA is a basic version of an explanatory factor analysis. Factor analysis and PCA are used to reduce dimensions, and often result in very similar outcome. We used rotation in our approach. As we intended to describe, rather than model our observations, we considered PCA more appropriate for this particular purpose. The statistics were calculated using the Statistical Package for Social Sciences (SPSS), version 23 (IBM SPSS Statistics, Armonk, NY). For reasons of legibility we show the absolute values of the loadings.

The measurements were in accordance with the ethical standards of the responsible institutional or regional committee on human experimentation at Humboldt-University of Berlin (former GDR) and in accordance with the Helsinki Declaration of 1975 as revised in 1983.

\section{RESULTS}

Figure 1 depicts Spearman-rho coefficients of correlations between height and head circumference; height and weight; 

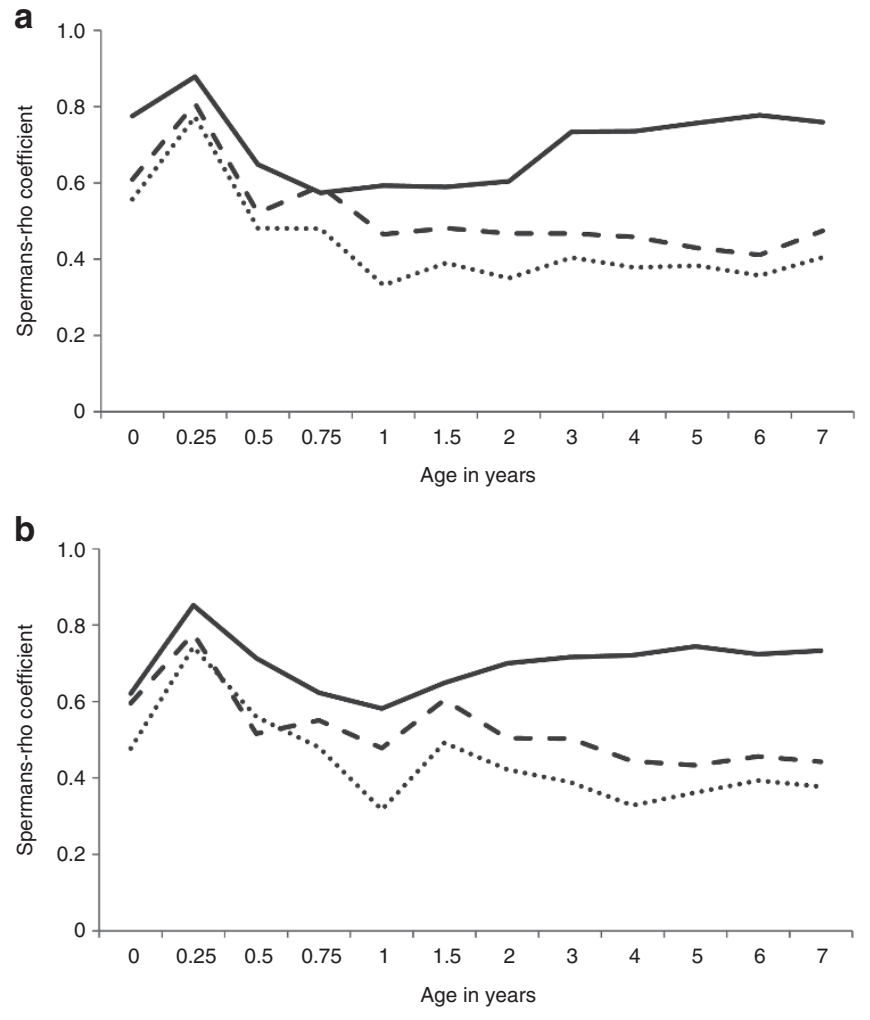

Figure 1. Correlation between height and head circumference (dotted line), height and weight (straight line), and weight and head circumference (dashed line) of 0-7 y old boys (a) and girls (b) (nonparametric correlation: Spearman's-rho); all coefficients are significant at the 0.01 level (two-tailed).

and weight and head circumference from birth to age $7 \mathrm{y}$, and nicely exemplifies the well-known correlations between these parameters during infancy and childhood -increases in body length (height) coincide with increases in body mass and increases in head size at all ages between birth and $7 \mathrm{y}$. Figures 2 and 3 illustrates that in spite of this general proportionality, body height, leg length, sitting height, biacromial shoulder breadth, thoracic breadth, thoracic depth, thoracic circumference, body weight, head volume, and percentage of body fat and hip skinfold vertical exhibit very different patterns. As presented in Table 1, three components are sufficient to explain between almost $60 \%$ and more than $75 \%$ of the cumulative variance. The parameters of skeletal growth-body height, leg length, sitting height, and also shoulder breadth, thoracic measures and body mass-predominantly load on the first component. Also head volume loads on this component, though only during the first $2 \mathrm{y}$ when due to early childhood proportions, head height (the difference between body height and tragion height) still account for more than 15\% of total body height. The parameters of skeletal growth and head volume clearly separate from the indicators of fat deposition-percentage of body fat, hip skinfold, and BMI-that predominantly load on the second component. Only during infancy, shoulder breadth and thoracic measures inconsistently also load on the "fat component".
After age $2 \mathrm{y}$, when the velocity of head volume growth slows down $\left(\mathrm{HV}=431.6 \pm 179.9 \mathrm{~cm}^{3}\right.$ in newborns, $\mathrm{HV}=$ $1,088.2 \pm 448.9 \mathrm{~cm}^{3} 1$ y old, $\mathrm{HV}=1,174.6 \pm 618.7 \mathrm{~cm}^{3} 2 \mathrm{y}$ old children) head volume starts to load on a separate third component in both sexes indicating that head growth is an independent process and proceeds independently of skeletal growth and fat acquisition.

\section{DISCUSSION}

The proportionality of human growth is well known (5): bigger babies have bigger heads. And since observational evidence suggests that well fed babies with bigger heads also do better (1) the general perception of a positive association between early linear growth and cognitive and motor development nicely fits the vision that effective nutrition interventions that are able to reduce linear growth restriction may also improve developmental outcomes (10).

We hypothesize that this vision might oversimplify the complex interaction between weight, height, and head circumference increments of the growing child and give rise to misinterpretation. In fact, the significant interrelations between the three parameters are deceptive. PCA reveals that in contrast to the popular perception, growth of the skeletal system, accumulation of fat (as indicator of nutritional richness) and the development of head size follow very different developmental paths: Incremental patterns of percentage of body fat differ from the incremental patterns of body length and both differ from the incremental patterns of head volume as already shown in adults $(11,12)$.

The fact that percentage of body fat is independent of body length, leg length, and sitting height during infant and child development supports recent evidence provided by Mumm et al. (13) who studied the association of body weight and weight variability in 833 modern and historic growth studies, and concluded that height gains and weight gains are subject to different regulations as already shown in a representative study on German adults $(11,12)$.

Our vision strongly questions current concepts that nutrition interventions can effectively reduce linear growth restriction and improve cognitive development. Larson and Yousafzai (14) meta-analyzed the effects of nutrition interventions on mental development in children under age $2 \mathrm{y}$ in low- and middle-income countries. The authors asked (i) do prenatal and postnatal nutritional inputs improve mental development? and (ii) are effects on mental development associated with physical growth and motor development? and concluded that motor development, but not growth status, effect sizes were significantly associated with mental development in postnatal interventions, but that nutrition interventions had only small effects on mental development. The missing effect of temporary malnutrition on brain growth was already noticed in an earlier study of German adults. Greil (12) showed that even those cohorts born between 1942 and 1948, i.e., during and shortly after World War II and raised under extreme nutritional and health conditions did not differ in head measures compared with those born before and thereafter. 
a

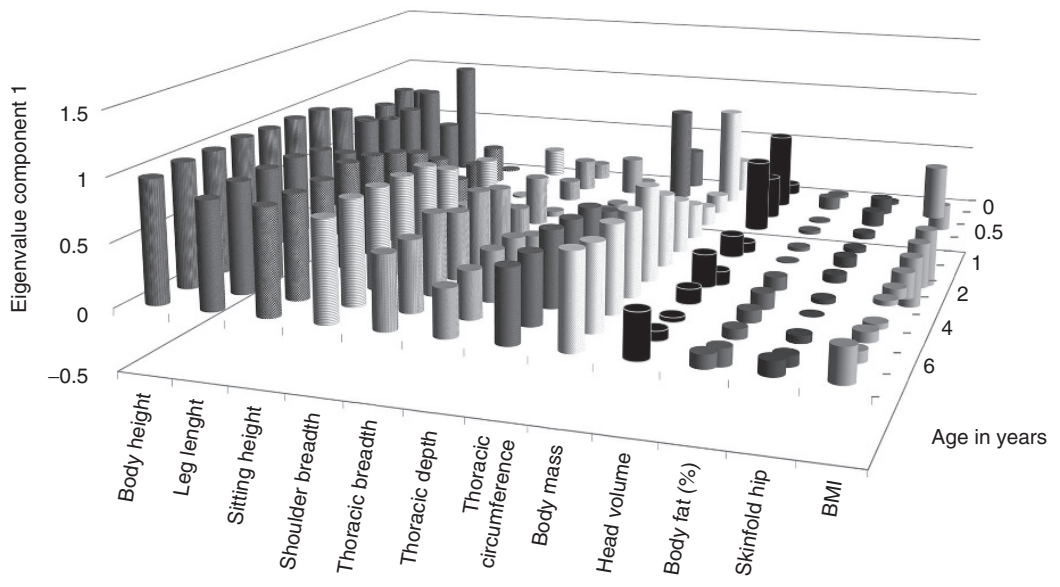

b

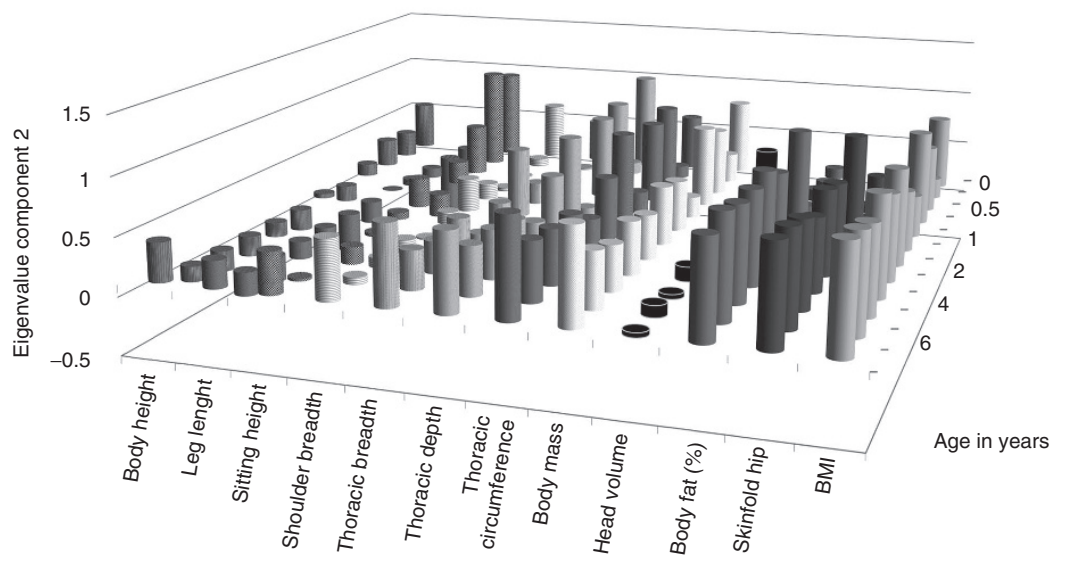

C

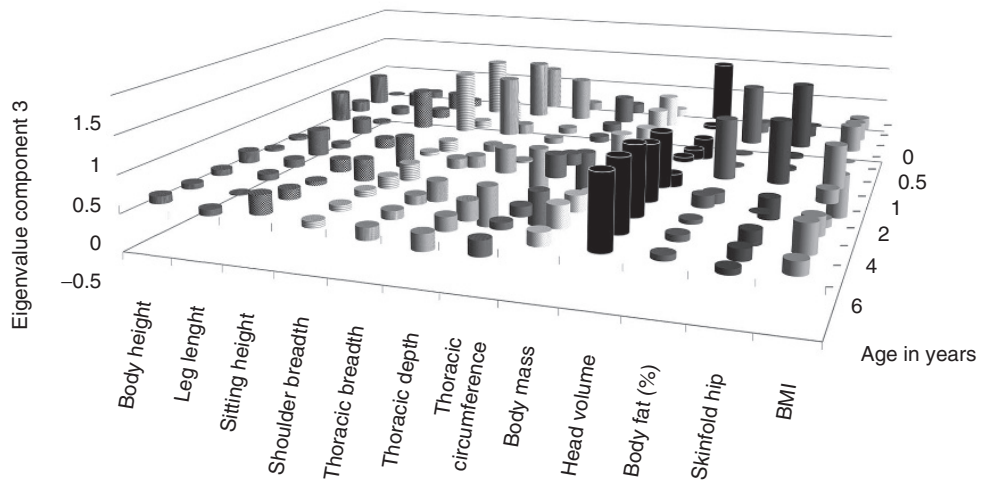

Figure 2. Eigenvalues of different body measurements of boys (newborn up to 7 y old). (a) Eigenvalues of component 1-height component of principal component analysis (PCA); (b) eigenvalues of component 2-body mass component; (c) eigenvalues of component 3-head component.

Not only macronutrients, also supplementation of micronutrients apparently lack an effect in mental development. Given the importance of micronutrients to proper cognitive development, Juaregui-Lobera (15) meta-analyzed the relevance of iron deficiency and iron deficiency anemia. They wrote the distinction between the cognitive consequences of iron deficiency and those affecting specifically cognitive development. They wrote, and the debate about the utility of iron supplements are the most relevant and controversial topics. They only found "some evidence that iron supplementation improves cognitive functions". WarthonMedina et al. (16) meta-analyzed the relationship between zinc intake, status, and indices of cognitive function in children and adults, but failed to show a significant effect of zinc supplementation on cognitive functioning in children. Other authors similarly failed to find clinically significant effects of micronutrient supplementation on head growth and cognitive function.

In contrast to the disappointing association between nutrition and cognitive development, Aboud and Yousafzai (17) highlighted the importance of adequate psychosocial stimulation to prevent children from developing expected cognitive and language abilities. In a systematic review and meta-analysis of 21 interventions aimed at enhancing stimulation and 


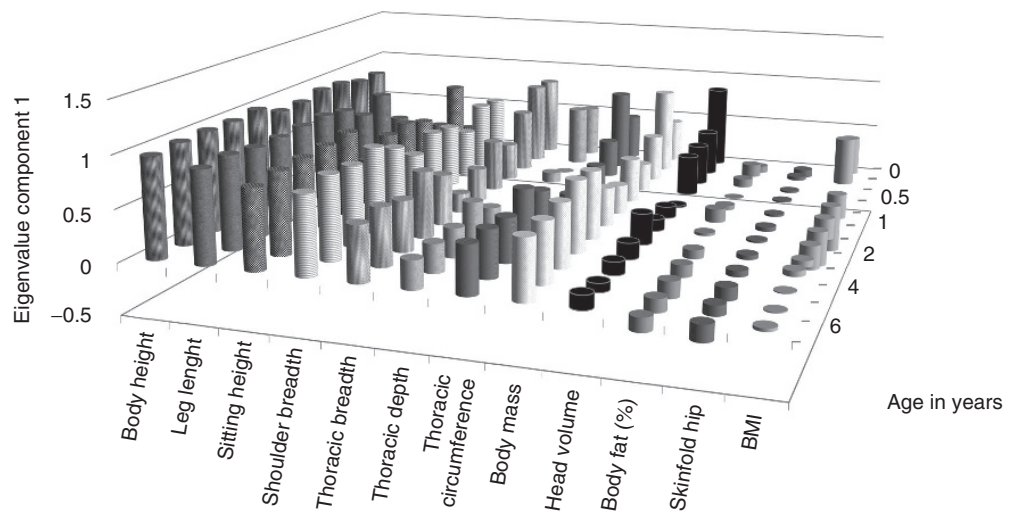

b

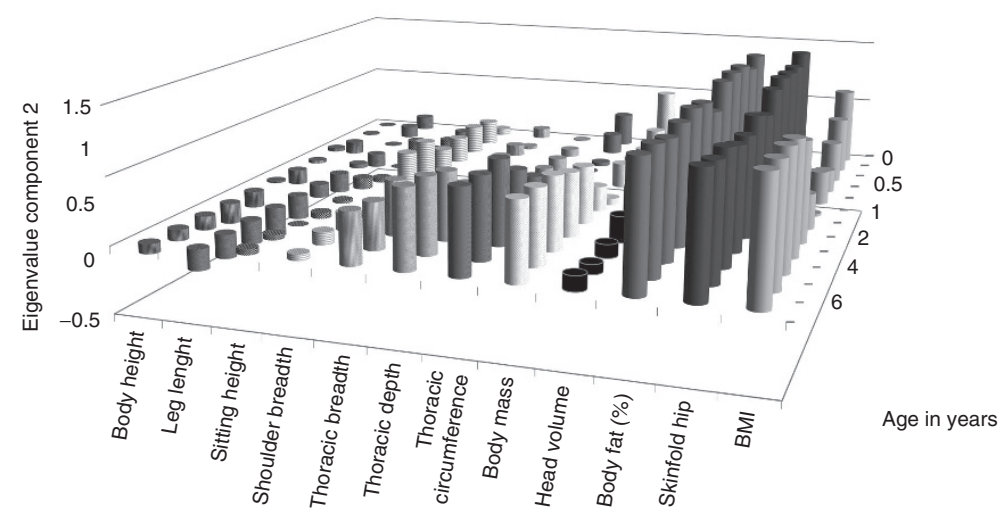

C

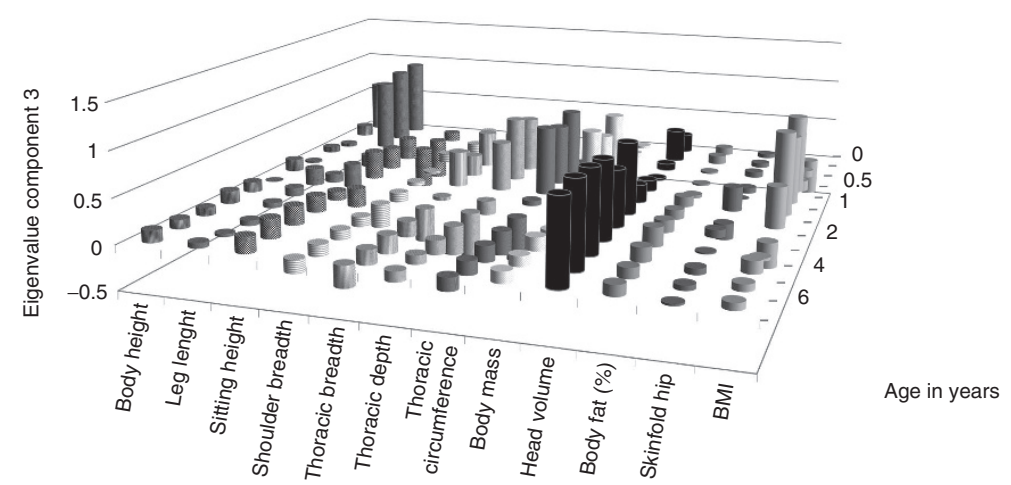

Figure 3. Eigenvalues of different body measurements of girls (newborn up to $7 \mathrm{y}$ old) of height component, body mass component, and head component of principal component analysis (PCA). The figure is constructed analogous to Figure 2.

18 interventions that provided better nutrition, they showed revealed that stimulation had a medium effect size of 0.42 and 0.47 on cognitive and language development, respectively, whereas nutrition by itself had only a small effect size of 0.09 .

Even though some authors suggest that food supplementation for improving the physical and psychosocial health may be effective for children of $<2 \mathrm{y}$, and for those who are poor and less well-nourished (18), there is a disappointing lack of evidence supporting the general idea that better nutrition will enhance later intellectual development. Under appropriate nutritional and health circumstances, nutritional status, body size, and head circumference are not related.

\section{KEYNOTE}

Skeletal growth, fat deposition, and head volume exhibit different incremental patterns. PCA can clearly separate skeletal growth and fat deposition suggesting that these parameters do not depend on each other.

After age $2 \mathrm{y}$, also head volume that initially closely follows the patterns of skeletal growth, starts to load on a separate component. 


\section{Articles | scheffler et al.}

The data indicate that nutrition supplementation will fail to significantly modify skeletal growth and head volume.

\section{ACKNOWLEDGMENTS}

This study was scientifically supported by the Auxological Society. Christiane Scheffler and Michael Hermanussen designed the project conception, development of overall research plan, and analyzed the data and performed the statistical analysis; Christiane Scheffler and Michael Hermanussen wrote the paper and have primary responsibility for the final content. Holle Greil conducted the data collection and added important aspects to the manuscript.

\section{STATEMENT OF FINANCIAL SUPPORT}

There are no sources of financial support.

Disclosure: The authors declare that they have no conflicts of interests.

\section{REFERENCES}

1. Prado EL, Dewey KG. Nutrition and brain development in early life. Nutr Rev 2014;72:267-84.

2. Correia HR, Balseiro SC, Correia ER, Mota PG, de Areia ML. Why are human newborns so fat? Relationship between fatness and brain size at birth. Am J Hum Biol 2004;16:24-30.

3. Räikkönen K, Forsén T, Henriksson M, et al. Growth trajectories and intellectual abilities in young adulthood: The Helsinki Birth Cohort study. Am J Epidemiol 2009;170:447-55.

4. Kuzawa CW, Chugani HT, Grossman LI, et al. Metabolic costs and evolutionary implications of human brain development. Proc Natl Acad Sci USA 2014;111:13010-5.

5. Thompson DW. On Growth and Form. Cambridge, UK: Cambridge University Press. 1942.

6. Knußmann R. Anthropologie - Handbuch der vergleichenden Biologie des Menschen. Vol 1: Wesen und Methoden der Anthropologie - 1. Teil: Wissenschaftstheorie, Geschichte, morphologische Methoden. Lehrbuchs der Anthropologie. 4th ed. Gustav Fischer: Stuttgart, 1988. pp.129.
7. Slaughter MH, Lohman TG, Boileau RA, et al. Skinfold equations for estimation of body fatness in children and youth. Hum Biol 1988;60: 709-23.

8. Manjunath KY. Estimation of cranial volume-an overview of methodologies J Anat. Soc. India 2002;51:85-91.

9. Field A. Discovering Statistics using SPSS Statistics.Los Angeles, London, New Dehli, Singapore, Washington DC: Sage, 2012. pp. 665-719

10. Sudfeld CR, McCoy DC, Danaei G, et al. Linear growth and child development in low- and middle-income countries: a meta-analysis. Pediatrics 2015;135:e1266-75.

11. Greil H. Mehrdimensionale Variabilität von Körpermaßen im Erwachsenenalter. Wissenschaftliche Zeitschrift der Humboldt-Universität, Berlin. 1988;36:212-221.

12. Greil H. Der Körperbau im Erwachsenenalter - DDR - repräsentative anthropologische Querschnittsstudie 1982/84. Dissertation (B). Berlin: Berlin Humboldt-Universität, 1988.

13. Mumm R, Ipsen MJ, Hermanussen M. The association of weight, weight variability and socioeconomic situation among children. Eur J Clin Nutr 2016;70:650-2.

14. Larson LM, Yousafzai AK. A meta-analysis of nutrition interventions on mental development of children under-two in low- and middle-income countries. Matern Child Nutr 2017;13. doi: 10.1111/mcn.12229.

15. Juaregui-Lobera I. Iron deficiency and cognitive functions. Neuropsychiatr Dis Treat 2014;10:2087-95.

16. Warthon-Medina M, Moran VH, Stammers AL, et al. Zinc intake, status and indices of cognitive function in adults and children: a systematic review and meta-analysis. Eur J Clin Nutr 2015;69:649-61.

17. Aboud FE, Yousafzai AK. Global health and development in early childhood. Annu Rev Psychol 2015;66:433-57.

18. Kristjansson E, Francis DK, Liberato S, et al. Food supplementation for improving the physical and psychosocial health of socio-economically disadvantaged children aged three months to five years. Cochrane Database Syst Rev. 2015;3:CD009924. doi: 10.1002/14651858.CD009924.pub2. 